\title{
Verbal fluency and emotional expression in young women differing in their styles of coping with threatening stimuli
}

\author{
Joanna Zinczuk-Zielazna ${ }^{A, B, C, D, E, F, G}$, Pawet Kleka ${ }^{B, C, D, E, F}$, Monika Obrębska ${ }^{B, D, E, F}$
}

Adam Mickiewicz University, Poznań, Poland

\section{BACKGROUND}

In our study we decided to examine whether anxiety defined in personality terms and various emotional states, including the state of fear, measured in two ways - by means of subjective rating scales and by means of a more objective method, the Facial Action Coding System (FACS) developed by Ekman, Friesen, and Hager - would affect emotional verbal fluency understood as the number of words generated in answer to a question about the most liked and disliked trait of one's personality.

\section{PARTICIPANTS AND PROCEDURE}

The participants in the screening test were 570 students; in this sample, we selected 90 women and classified each of them into one of three groups - high-anxious individuals $(n=23)$, low-anxious individuals $(n=41)$, and repressors $(n=26)$ - distinguished based on the criteria proposed by Weinberger and colleagues. The research task, whose aim was to induce emotions, consisted in delivering a speech lasting a few minutes in front of an audience and a video camera.
RESULTS

We obtained evidence of a significant association between emotional states and verbal fluency. Fear recognized by means of the FACS turned out to be the emotion that was the most strongly correlated with overall verbal fluency. We found no significant differences in fluency between individuals differing in terms of trait anxiety: low-anxious, high-anxious, and repressors.

\section{CONCLUSIONS}

The structure of results shows that the participants' loquaciousness in the situation of speaking in front of an audience was more strongly influenced by currently experienced emotions than by the stable personality trait of anxiety.

\section{KEY WORDS}

verbal fluency; emotion; emotional expression; anxiety; coping style

Corresponding Author - Joanna Zinczuk-Zielazna, Ph.D., Adam Mickiewicz University, 89 Szamarzewskiego Str., 60-568 Poznań, Poland, e-mail: jzinczuk@amu.edu.pl

AUthors' CONTRiBution - A: Study design - B: Data collection - C: Statistical analysis - D: Data interpretation .

E: Manuscript preparation · F: Literature search · G: Funds collection

TO Cite this ARTICLE - Zinczuk-Zielazna, J., Kleka, P., \& Obrębska, M. (2018). Verbal fluency and emotional expression in young women differing in their styles of coping with threatening stimuli. Current Issues in Personality Psychology, 6(4), 330-342. 


\section{BACKGROUND}

Verbal fluency can be defined as the ease of articulation, the ability to utter strings of words at a particular speed, and an indicator of linguistic fluency. In the field of psychology, it is usually defined as the ability to generate words according to a particular criterion. The criterion may be associative, when the person is supposed to give the largest possible number of words that "come to mind" in a given amount of time (associative fluency); it may be semantic, when the task consists in enumerating items belonging to a given semantic category (semantic fluency); or it may be affective, when associations concern emotional categories, such as "pleasant" and "unpleasant" (affective fluency). Quantitative parameters of fluency task accomplishment are usually considered as performance indicators; analyses of qualitative aspects of performance are less frequent (Gawda \& Szepietowska, 2015; Szepietowska \& Gawda, 2011).

Tasks requiring spontaneous generation of words according to an associative, semantic, or affective criterion constitute an important assessment instrument that makes it possible to measure both cognitive functions and emotional processes without burdening the client. Fluency as a diagnostic technique is used to the fullest extent in neuropsychological studies, for instance in the description of verbal expression disturbances in the course of aphasia; it is also widely applied in the psychology of cognitive processes and emotions, in clinical psychology, and in speech therapy. It is determined both by personal factors, such as age, sex, cognitive and emotional processes, and by situational factors, connected with the type of task and the characteristics of the social context (Gawda \& Szepietowska, 2011; Obrębska \& Kleka, 2016).

\section{AFFECTIVE FLUENCY}

Affective fluency, consisting in generating words from affect categories, requires the activation of episodic aspects of autobiographical memory, which the person evaluates positively or negatively from the perspective of his or her personal experience, and semantic aspects, which make it possible to generate general affect-saturated concepts. However, this technique activates not only linguistic and memory processes but also affective states and personality traits (Szepietowska \& Gawda, 2011).

Affective fluency is attained based on the cooperation of prefrontal areas, the hippocampus formation, thalamic nuclei, and especially the amygdalae, whose connections with the hippocampus enable the formation of memory traces together with the emotional and situational context (Daniluk \& Szepietowska, 2009). Consequently, brain aging processes have a significant influence on the level of affective fluency: in generating words from particular affective categories, older individuals usually score lower than younger people. This is the case particularly in men. Women, regardless of age, scored higher on affective fluency than men, whose ability to generate affectsaturated words decreased with age (Tabert, Peery, Borod, Schmidt, Grunwald, \& Sliwinski, 2001).

Studies on fluency are usually conducted in the context of the influence of emotional states on performance in tasks measuring verbal fluency. They may be either quantitative or qualitative, when the aim is, for instance, to reconstruct the relations between words (Schwartz, Baldo, Graves, \& Brugger, 2003), to study emotional intelligence (Jasielska, 2007), or to describe the internal structure of emotional concepts. Using the affective fluency method, Barbara Gawda and Małgorzata Szepietowska (2015) performed a conceptual reconstruction of happiness and fear, which showed that verbal fluency, treated as a measure of linguistic abilities, may also be a way of gaining access to the contents of concepts and emotional schemas.

\section{EMOTIONAL STATES AND VERBAL FLUENCY}

According to Szepietowska and Gawda (2011), the relations between emotional states and verbal fluency should be seen in a broader context of relations between cognitive and emotional processes. Many studies confirm the associations between the levels of depression or anxiety and difficulties in learning and recall. These are the most visible in individuals with emotional disorders, especially if they dominate the clinical picture. For example, studies on the disturbances of fluency mechanisms in individuals diagnosed with depression involve the analysis of many cognitive functions: memory, attentional processes, and information processing speed. What is especially highlighted in neuronal studies on fluency mechanisms in depression is the significance of frontal lobe dysfunction and deficits in executive functions; this means verbal fluency disturbances reflect more general information processing disturbances (Atchley, Hardi, \& Enole, 2003; Calev, Nigal, \& Chazan, 1989; Szepietowska \& Gawda, 2011).

Also characteristic of depression is a bias in information processing. Individuals with depression more quickly recognize and more easily recall words with negative emotional valence than individuals from the control group; the results were the reverse in the case of positive valence. This is explained as stemming from attention bias in depressive individuals, with a focus on negative material, consistent with low mood. Depressive people's attention is more sensitive to negative emotional stimuli, which is re- 
flected in the stronger activation of the P200 wave in the event-related potential (ERP) during the performance of tasks on affective material. Similar relations have been observed in the case of trait anxiety: anxious people modify the perception of reality in such a way that they mark various stimuli with negative emotional valence, which also contributes to the negative character of affective fluency (Gawda \& Szepietowska, 2012; Gawda \& Szepietowska, 2011).

In the case of high mood, contradictory results have been obtained: in some studies there was an improvement and in others a deterioration in verbal fluency. Bartolic, Basso, Schefft, Glauser, and TitanicSchefft (1999) experimentally induced good mood and dysphoria in participants; high mood strongly correlated with a high level of verbal fluency. In a study by Clark, Iversen, and Goodwin (2001), participants in a more negative mood scored higher on fluency than participants in a positive mood.

The influence of anxiety on verbal expression has been studied mainly in the context of utterance content analysis (Gawda, 2007) or in the context of the participants' lexical choices (Obrębska \& ZinczukZielazna, 2016; Zinczuk-Zielazna \& Obrębska, 2016). Strong emotions in the form of tension or anxiety have a disorganizing effect on the character of utterances, manifesting itself, among other symptoms, in fluency disturbances. For example, a strong relationship has been found between stuttering and anxiety, stemming from the special predisposition of the autonomic nervous system to increased reaction to stressful factors (Alm, 2004). The study by EzratiVinacour and Levin (2004), conducted on a group of 94 men, also confirmed that stuttering men exhibited a higher level of social and task anxiety.

In studies on schizophrenia, researchers have observed an association of positive symptoms and high anxiety with loquaciousness. Patients with positive symptoms generated significantly longer utterances (on average, 1500 words) compared to patients with negative symptoms (300 words) and normal individuals (300 words). At the same time, their utterances exhibited lower coherence and comprehensibility (Obrębska, 2013). Likewise, studies on schizotypy and verbal fluency support the thesis postulating a relationship between anxiety and verbal fluency (Tsakanikos \& Claridge, 2005).

Vocalized pauses, silent pauses, and repetitions of the same words are considered to be criteria of speech fluency disorders, because they reflect the anxious arousal of the speaker (Morreale, Spitzberg, \& Barge, 2001). Mahl (1987b) in his research devoted a lot of attention to pauses, disruptions and "small" parts of speech such as pronouns, conjunctions and particles, which in his opinion occur in utterances more often if a speaker is experiencing anxiety. He examined the utterances of patients during psychotherapy (Mahl, 1956), the language of children regarded as anxious (Zimbardo, Mahl, \& Barnard, 1963) and spontaneous speech of healthy individuals in situations arousing anxiety (Kasl \& Mahl, 1965; Mahl, 1987a). He stated that the proportion of the number of disruptions to the overall number of uttered words is positively correlated with anxiety. The proportion may be therefore considered to be a measure of the speaker's anxiety.

Argaman (2010) explored possible relationships between the intensity of emotions and the lexical modalities for expressing those emotions. Based on an experiment in which participants described the emotions experienced while watching films, he distinguished a number of verbal indicators of high emotional intensity, such as repetitions of the same words, vocalized pauses and others. This experiment confirmed that significant differences exist between the lexical modalities found in texts produced with lower emotional intensity and those produced with greater emotional intensity.

It is also confirmed by the result of the research on lexical choices of individuals suffering from schizophrenia (Obrębska \& Obrębski, 2007): the number of vocalized pauses, repetitions, particles, conjunctions and pronouns in the utterances of ill individuals was significantly higher than in the utterances of healthy individuals, which can be related to a high level of anxiety accompanying schizophrenia.

Szepietowska and Gawda (2011) stress that difficulties in investigating the relations between anxiety and verbal fluency stem mainly from the fact that the category of anxiety may be understood in very different ways: "as a state of emotional tension, as a personality trait being a predisposition to react anxiously (in very different situations), and as a characteristic integrated into other personality traits" (p. 45). Anxiety can therefore be understood, firstly, as a temporary and situationally determined emotional state, manifesting itself in specific physiological changes (such as quickened pulse and breath), behavioral changes (such as facial expression), and subjective experiences marked by fears and cognitive disturbance. State anxiety is considered to be "the emotional component of risk assessment behavior in contrast to fear or panic, which is viewed as the emotional accompaniment of flight" (Blanchard \& Blanchard, 2008; Perkins, Inchley-Mort, Pickering, Corr, \& Burgess, 2012, p. 910). The second perspective on anxiety consists in treating it as a relatively stable personality trait which makes a person likely to perceive objectively harmless situations as threatening and to react to them disproportionately with states of strong anxiety. A popular questionnaire whose structure is based on the distinction between state anxiety and trait anxiety is STAI - Spielberger's StateTrait Anxiety Inventory, which has been adapted into Polish by Wrześniewski, Sosnowski, and Matusik (2002). 
Interesting relationships were observed when this distinction was introduced. Situational anxiety turned out not to be linked in any way with verbal fluency, while trait anxiety fostered a focus on emotionally negative stimuli. What underlies this effect of anxiety is the mechanism of attentional bias, which - as in the case of depression - leads to a stronger focus on negative or threatening stimuli. As a result, anxious individuals generate more negative associations in affective fluency tests than individuals low in anxiety. High trait anxiety can also reduce the focus of attention and impair the ability to generate words in the case of nonaffective (associative or semantic) fluency (Szepietowska \& Gawda, 2011).

In our study we decided to examine whether trait anxiety and various emotional states measured in two ways - with subjective rating scales and by means of a more objective method, the Facial Action Coding System (FACS) developed by Ekman, Friesen, and Hager (2002) - would affect verbal fluency understood as loquaciousness, i.e. the number of words generated.

\section{TRAIT ANXIETY AS A PERSONALITY VARIABLE}

Trait anxiety was conceptualized in accordance with the conception of styles of coping with threatening stimuli, originated by Weinberger, Schwartz, and Davidson (1979). This theory is based on the observation that the group of persons exhibiting a low level of trait anxiety in studies using questionnaire-based methods (such as the State-Trait Anxiety Inventory; Spielberger, Gorsuch, Lushene, Vagg, \& Jacobs, 1983) consists of at least two subgroups. The first subgroup comprises individuals who actually have a low level of anxiety, while the second comprises those who exhibit a low level of anxiety in their self-descriptions but react to stressful situations with a high degree of physiological and behavioral agitation. It was found that persons in the second subgroup, described as repressors, scored high on scales used to measure defensiveness (such as the Social Desirability Scale; Crowne \& Marlowe, 1960, 1964), which, among other purposes, serve to measure the degree to which test results are falsified.
Analyzing the results obtained by participants on scales measuring trait anxiety and the tendency to react in a socially approved manner, Weinberger et al. (1979) distinguished four groups of people with different styles of coping with threatening stimuli: "truly low-anxious," "high-anxious," "repressors," and "defensive high-anxious" (Figure 1).

According to the original study and the ones by Myers (2000, 2010), members of each of the four groups have a tendency to behave in a characteristic manner. The first group consists of truly lowanxious individuals, who score low on both anxiety and defensiveness. In low-anxious individuals, who are described as carefree, light-hearted, and calm, a low level of anxiety is found in self-descriptions and in behavioral as well as physiological indicators of emotional processes. The second group consists of high-anxious individuals, who are characterized by a high level of trait anxiety and low defensiveness. High-anxious individuals exhibit a tendency to pay attention to threatening stimuli rather than to neutral ones when both are presented simultaneously and a tendency to interpret ambivalent stimuli as threatening (Eysenck, 2000). Consequently, these individuals experience anxiety strongly and willingly talk about those experiences, disclosing details from their private life which are not required in the study (Myers, 2010).

The next group consists of people classified as repressors, who score low on trait anxiety and high on defensiveness. The results of studies in this area show that repressors have little tendency to experience anxiety consciously (during a stressful task), but at the same time exhibit a high level of anxiety through physiological and behavioral indicators (e.g., Asendorph \& Scherer, 1983; Derakshan \& Eysenck, 1997a, 1997b, 2001a, 2001b). Some researchers (Weinberger \& Davidson, 1994) assume that repressors report experiencing a substantially lower intensity of emotions as compared to the level of their physiological and expressive arousal because they apply defensive self-deception strategies and are deeply convinced that they are not inclined to experience anxiety and other negative emotions. For instance, these people have low tolerance of emotional ambivalence, are particularly skillful in diverting attention away from
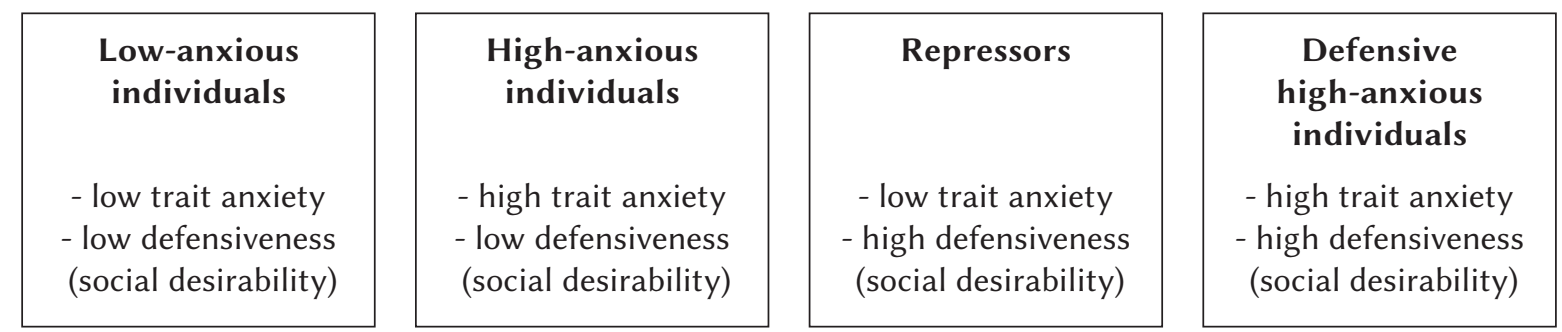

Figure 1. Four styles of coping with threatening stimuli as defined by Weinberger et al. (1979). 
the stimuli they want to ignore, and exhibit high motivation to maintain a positive self-image (Derakshan \& Eysenck, 1999; Eysenck, 2000).

The final group consists of defensive high-anxious individuals, who score high on both trait anxiety and defensiveness. They constitute a group that is, so far, the least well known. Defensive high-anxious individuals are described as experiencing embarrassment and worry, expressing discomfort in situations involving the disclosure of information required in studies.

\section{RESEARCH PROBLEM AND HYPOTHESES}

The authors of the present study were interested in whether anxiety understood as a personality trait, in terms of the style of coping with threatening stimuli, would influence verbal fluency understood as loquaciousness - the number of words generated - in answer to the question. Based on the studies discussed above, we assumed that high anxiety occurred not only in high-anxious individuals but also in repressors, according to the typology proposed by Weinberger and colleagues. The second question that the authors posed was the following: Will different emotional states affect verbal fluency? In response to the research problems and based on the analyzed literature, we formulated the following hypotheses:

$\mathrm{H} 1$ : We postulated a difference in the overall level of verbal fluency between individuals representing different coping styles according to Weinberger et al. (1979); we hypothesized higher verbal fluency for high-anxious individuals and repressors and lower verbal fluency for low-anxious individuals. We also hypothesized that repressors would exhibit higher verbal fluency compared to the remaining groups in answer to the question about the liked personality trait, due to the tendency of these people - well documented in research - to attribute socially desirable traits to themselves. In high-anxious individuals, by contrast, we hypothesized higher verbal fluency compared to the remaining groups in answer to the question about the disliked personality trait, as these people have a tendency to focus on threatening stimuli.

H2: The emotional states, estimated on the basis of facial behaviors, intensify verbal fluency. Happiness intensifies verbal fluency in answer to the question about the liked character trait. Negative emotions such as fear, anger, sadness, disgust, and contempt intensify verbal fluency in answer to the question about the disliked character trait.

H3: The experienced (self-reported) emotional states intensify verbal fluency. The experienced positive emotional states such as happiness or pride intensify verbal fluency in answer to the question about the liked character trait. The experienced negative emotional states such as fear, anxiety, anger, sadness, shame, disgust, and contempt intensify verbal fluency in answer to the question about the disliked character trait.

H4: We also hypothesized that speech fluency disorders - in the form of vocalized pauses (e.g., "erm”), silent pauses (“...), and repetitions of the same words (e.g., "that, that") - would correlate both with high-anxious and repressive coping styles and with particular emotional states.

\section{PARTICIPANTS AND PROCEDURE}

\section{PARTICIPANTS}

To test the above hypotheses, we carried out a twostage study. In the first stage, we used a questionnaire survey to select groups of people with particular coping styles as described by Weinberger et al. (1979). The respondents were 570 students in 14 different study courses (special teacher training, general teacher training, philosophy, political science, cognitive science, biology, geography, environmental protection, Polish language, English language, history, music, history of art, archeology). The participants' mean age was $20.72( \pm 1.67$, range $18-32)$, and all of them were Polish. The respondents completed the Trait Anxiety Scale by Spielberger et al. as adapted into Polish by Wrześniewski et al. (2002), and the MarloweCrowne Social Approval Scale as adapted into Polish by Siuta (1989).

The laboratory testing stage involved 90 women. The participants' mean age was $19.72( \pm 1.41$, range $18-26)$. The gender variable is significant when considering the predisposition to experience anxiety. Some studies show women to have higher levels of anxiety than men; for example, in a study by Noël, Lewis, Francis, and Mezo (2013) women exhibited significantly higher anxiety than men according to the Anxiety Sensitivity Index (ASI; Reiss, Peterson, Gursky, \& McNally, 1986) and the Penn State Worry Questionnaire (PSWQ; Meyer, Miller, Metzger, \& Borkovec, 1990). Similarly, a study by Keogh (2004) confirmed the assumption that there are differences between men and women in anxiety sensitivity (AS) women reported higher levels of AS than men. There is evidence that gender can moderate the strength of correlation between implicit and explicit measures; for example, Donges, Jachmann, Kersting, Egloff, and Sulsow (2015) found a link between attachment anxiety and implicit self-concept of neuroticism in women but not in men. We therefore decided to restrict the present sample to women only. Men will be tested in a separate study, which will consequently enable the identification of possible differences be- 
tween the sexes in the propensity to use explainers in situations when anxiety is experienced.

Based on the clustering of the data into four clusters "around medoids", which is a more robust version of $k$-means clustering (Reynolds, Richards, de la Iglesia, \& Rayward-Smith, 1992), we classified each woman into one of three groups - repressors (26 participants), high-anxious individuals (23) and low-anxious individuals (41). Because cluster analysis with the $k$-means method did not yield a characteristic cluster for defensive high-anxious individuals, we did not include that group in the study. The distinguished groups differed significantly in terms of anxiety trait $\left(F(2,87)=156.26, p<.001, \eta_{\text {part. }}^{2}=.78\right)$, and the Marlowe-Crowne Social Approval Scale $\left(F(2,87)=119.68, p<.001, \eta_{\text {part. }}^{2}=.73\right)$.

\section{PROCEDURE}

The participants $(N=90)$ were assigned a task that could be potentially stressful - to give a speech lasting several minutes in front of an audience consisting of two expert psychologists. The speech was to concern the participant's personality traits that the participant liked and disliked. Each participant had approximately 10 minutes to prepare the speech, and then went to a different room, where the audience was waiting. First, the women freely spoke about the trait that they liked the most about themselves and about the one they disliked the most. Next, the audience asked them eight standard questions:

- Is there any other trait of your personality that you do not like?

- Is there any other trait of your personality that you like?

- In your opinion, what traits do people like about you?

- In your opinion, what traits do people not like about you?

- Please reveal some negative aspect of yourself that your friends are not aware of.

- Do you consider yourself attractive?

- Is this conversation difficult for you?

- Would you like to add anything?

The speech was recorded by means of a digital video camera, the presence of which constituted another potential stress factor. All study participants were informed about the video recording before the experiment and provided written consent.

\section{MEASUREMENT TECHNIQUES}

We adopted several measures of verbal fluency. Firstly, we measured the overall number of words in each participant's entire speech in front of the audience ( $M=634 \pm 350$, range 183-2932). Secondly, we mea- sured the number of words generated in answer to the initial question about the most liked trait of the participant's own personality $(M=120 \pm 77$, range 26-509) and the number of words generated in answer to the initial question about the most disliked personality trait $(M=133 \pm 121$, range $36-1092)$. We also measured three types of speech fluency disorders: the number of vocalized pauses (e.g., "erm", $M=22, M d=10$, range $0-160)$, the number of silent pauses $(M=35, M d=9$, range $0-185)$, and the number of repetitions of the same words (e.g., "that, that", $M=4, M d=3$, range $0-47$ ).

Facial behaviors - brief changes in the appearance of the participants' faces, caused by muscle contractions - were analyzed by means of the Facial Action Coding System (FACS), constructed by Ekman and Friesen (1978) and updated 24 years later by Ekman, Friesen, and Hager (2002). The FACS is currently the most elaborate and reliable system for measuring facial expressions. In the FACS procedure, facial behaviors previously recorded with a digital camera are analyzed by a person trained to do it - in real time and in slow motion (Draheim, 2001). After coding the participants' facial behaviors, signatures are compared with the FACSAID database (FACS Affect Interpretation Dictionary), which contains interpretations - in terms of emotions - of specific expressions described in the FACS language. The method is based on the Darwinian view, shared by contemporary psychologists, that facial expressions of emotion are essentially innate. This conclusion is based on studies showing that facial expressions of emotions generalize across cultures (e.g., Ekman \& Friesen, 1971). FACS makes it possible to identify the facial indicators of the following emotions: happiness $(M=14.05 \pm 6.52$, range $3-20)$, sadness $(M=0.40 \pm 1.15$, range $0-1)$, anger $(M=1.00 \pm 1.66$, range $0-2)$, fear $(M=1.40 \pm 2.10$, range $0-3)$, surprise $(M=0.10 \pm 0.34$, range $0-1)$, disgust, $(M=1.20 \pm 2.20$, range $0-4)$ and contempt $(M=0.90 \pm 1.17$, range $0-1)$. The FACS coder who has analyzed the mimic behaviors manifested by the participants has an individual certificate entitling him to use the FACS. The FACS coder's coefficient of compliance with the expert was 0.82 and was higher at a statistically significant level than the required minimum of 0.70 .

Self-report rating scales on which the participants indicated what emotions they experienced while performing the task of making a speech in front of the audience contained 11 categories - names of emotions: happiness $(M=1.90 \pm 1.97$, range $0-5)$, sadness $(M=0.70 \pm 1.09$, range $0-1)$, anger $(M=0.40 \pm 0.73$, range $0-1)$, fear $(M=1.10 \pm 1.53$, range $0-3)$, surprise $(M=1.90 \pm 1.21$, range $0-1)$, embarrassment $(M=3.40 \pm 2.20$, range $0-6)$, shame $(M=1.50 \pm 1.66$, range $0-3)$, disgust $(M=0.20 \pm 0.51$, range $0-1)$, contempt $(M=0.20 \pm 0.57$, range $0-1)$, and pride $(M=1.20 \pm 1.39$, range $0-3)$. The rating of emotions 
(experienced while making a speech in front of an audience) took place in a different room, when the participant was listening to the audio recording of her speech. This was meant to facilitate the recall of the emotions experienced. This method is a modified version of the instrument called cued-review technique, developed by Ekman and Rosenberg (1997). Listening to the recording, the person marked on the timeline the category of emotion and the moment when it occurred. This procedure allowed data on the category and frequency of experienced emotions to be obtained.

\section{RESULTS}

\section{DIFFERENCES IN VERBAL FLUENCY ACCORDING TO THE LEVELS OF ANXIETY AND REPRESSION}

We postulated the existence of a marked difference in the level of verbal fluency between participants, assuming that truly low-anxious individuals would score higher than the other two groups. However, the analysis of variance in fluency scores revealed a lack of differences in the means across the groups $\left(F(2,87)=2.59, p=.111, M_{\mathrm{la}}=523 \pm 205, M_{\mathrm{rp}}=577 \pm 259\right.$, $M_{\text {ha }}=697 \pm 492$ ).

We expected that verbal fluency for positive self-presentation would be higher in repressors than in the remaining groups, but the analysis of the results did not confirm this hypothesis $(F(2$, $87)=0.60, p=.549, M_{\mathrm{la}}=117 \pm 71, M_{\mathrm{rp}}=112 \pm 49$, $\left.M_{\text {ha }}=135 \pm 108\right)$.

The hypothesized higher verbal fluency in highanxious individuals in the case of answer to the question about the disliked character trait was not confirmed, either - mean scores did not differ across the groups $\left(F(2,87)=1.94, p=.151, M_{\mathrm{la}}=123 \pm 72\right.$, $\left.M_{\mathrm{rp}}=112 \pm 39, M_{\mathrm{ha}}=175 \pm 215\right)$.

In the analysis of pauses, we found no differences between the groups in terms of vocalized pauses $\left(F(2,87)=0.27, p=.766, M_{\mathrm{la}}=24.50 \pm 27.30\right.$, $\left.M_{\mathrm{rp}}=21.40 \pm 33.50, M_{\mathrm{ha}}=18.70 \pm 35.40\right)$ or in the number of fluency disorders $(F(92,87)=3.03, p=.053$, $\left.M_{\mathrm{la}}=3.46 \pm 2.96, M_{\mathrm{rp}}=3.96 \pm 6.43, M_{\mathrm{ha}}=7.39 \pm 9.76\right)$. We did find significantly fewer silent pauses in the highanxious group $\left(F(2,87)=354, p=.015, M_{\mathrm{la}}=40.80 \pm 45.50\right.$, $\left.M_{\mathrm{rp}}=48.00 \pm 53.60, M_{\mathrm{ha}}=12.90 \pm 24.20, \eta_{\text {part. }}^{2}=.09\right)$.

\section{RELATIONS BETWEEN VERBAL FLUENCY AND EMOTIONAL STATES}

To test the hypothesis postulating associations between fluency and emotional states, we used Pearson's $r$ correlation coefficient. Because each participant was examined in terms of many emotional dimensions, we used Holm's adjustment for the significance level of correlation coefficients.

In the case of emotions measured with the FACS, the one that turned out to be a significant predictor of fluency, regardless of its type, was fear $(r=.54)$. It correlated positively with the number of words uttered. A similar though weaker effect was found in the case of the relationship between surprise and fluency $(r=.37)$ - individuals exhibiting more facial symptoms of surprise uttered more words in their speech both about their positive trait and about the negative one. We also found a moderate correlation between overall fluency and happiness. By contrast, the correlation with the general category of negative emotions measured by the FACS is a consequence of a strong correlation with fear (Table 1).

Table 1

Correlation coefficients and level of significance between fluency and the emotions measured with the FACS

\begin{tabular}{lrrrrrr}
\hline & \multicolumn{2}{c}{ Fluency } & \multicolumn{2}{c}{ Positive fluency } & \multicolumn{2}{c}{ Negative fluency } \\
\cline { 2 - 7 } & $r$ & $p$ adj. & $r$ & $p$ adj. & $r$ & $p$ adj. \\
\hline Happiness & .34 & .004 & .15 & .129 & -.001 & .496 \\
Surprise & .37 & .002 & .33 & .005 & .38 & .002 \\
Fear & .54 & $<.001$ & .42 & $<.001$ & .41 & .001 \\
Disgust & .21 & .051 & .08 & .264 & .21 & .058 \\
Contempt & -.02 & .450 & .05 & .367 & -.02 & .430 \\
Anger & -.04 & .370 & .03 & .404 & -.01 & .456 \\
Sadness & .17 & .100 & .08 & .278 & .02 & .430 \\
Negative emotions & .36 & $<.001$ & .17 & .058 & .26 & .006 \\
\hline
\end{tabular}

Note. $r$ - Pearson's correlation coefficient; $p$ adj. - one-tailed significance of the correlation coefficient with Holm's adjustment for multivariate testing. 
Table 2

Correlation coefficients and level of significance between fluency and the emotions measured with self-report scales

\begin{tabular}{lrrrrrr}
\hline & \multicolumn{2}{c}{ Fluency } & \multicolumn{2}{c}{ Positive fluency } & \multicolumn{2}{c}{ Negative fluency } \\
\cline { 2 - 7 } & $r$ & $p$ adj. & $r$ & $p$ adj. & $r$ & $p$ adj. \\
\hline Happiness & .38 & $<.001$ & .47 & $<.001$ & .34 & .001 \\
Sadness & .27 & .006 & .27 & .005 & .14 & .094 \\
Anger & -.03 & .404 & .07 & .260 & .11 & .163 \\
Fear & .14 & .087 & .07 & .262 & .12 & .125 \\
Surprise & .07 & .257 & .02 & .421 & .08 & .218 \\
Embarrassment & -.02 & .446 & -.09 & .207 & .01 & .481 \\
Shame & .45 & $<.001$ & .36 & $<.001$ & .49 & $<.001$ \\
Disgust & .10 & .176 & .11 & .144 & .02 & .431 \\
Contempt & .01 & .473 & .10 & .181 & .02 & .428 \\
Pride & .26 & .007 & .44 & $<.001$ & .22 & .017 \\
\hline
\end{tabular}

Note. $r$ - Pearson's correlation coefficient; $p$ adj. - one-tailed significance of the correlation coefficient with Holm's adjustment for multivariate testing.

In the case of pauses, a high score on the Fear scale of the FACS increased the number of vocalized pauses $(r=.40, p=.001)$ and fluency disorders $(r=.47$, $p<.001)$, while happiness increased the number of silent pauses $(r=.31, p=.009)$.

We performed a similar analysis for scores on self-report scales. In this case, the main variables that correlated with fluency were: shame $(r=.45)$, happiness $(r=.38)$, and, to a smaller degree, pride $(r=.26)$ : the higher the scores on these scales were, the higher was the overall fluency. Positive fluency was correlated positively, though weakly, with sadness $(r=.27)$ and more strongly with happiness $(r=.47)$ and pride $(r=.44)$ (Table 2).

In the analysis of the influence of scores on self-report scales measuring emotions on the number of vocalized pauses, we found a positive association with happiness $(r=.35, p<.001)$, sadness $(r=.30, p=.002)$, shame $(r=.36, p<.001)$, disgust $(r=.26, p=.008)$, and pride $(r=.22, p=.018)$. The number of silent pauses is influenced by the scores on scales measuring happiness $(r=.25, p=.010)$, disgust $(r=.31, p=.002)$, and pride $(r=.31, p=.002)$. The factors increasing fluency disorders are: sadness $(r=.38, p<.001)$, shame $(r=.44, p=.001)$, and disgust $(r=.29, p=.002)$.

Figure 2 displays the relationship between verbal fluency and emotions measured by FACS and self-report scales. Due to their higher resistance to self-deception, scores on FACS scales should correlate with verbal fluency more strongly than scores on self-report scales, if the theory is true.

For particular emotions measured by means of both instruments, we examined the differences between the correlation coefficients with the general

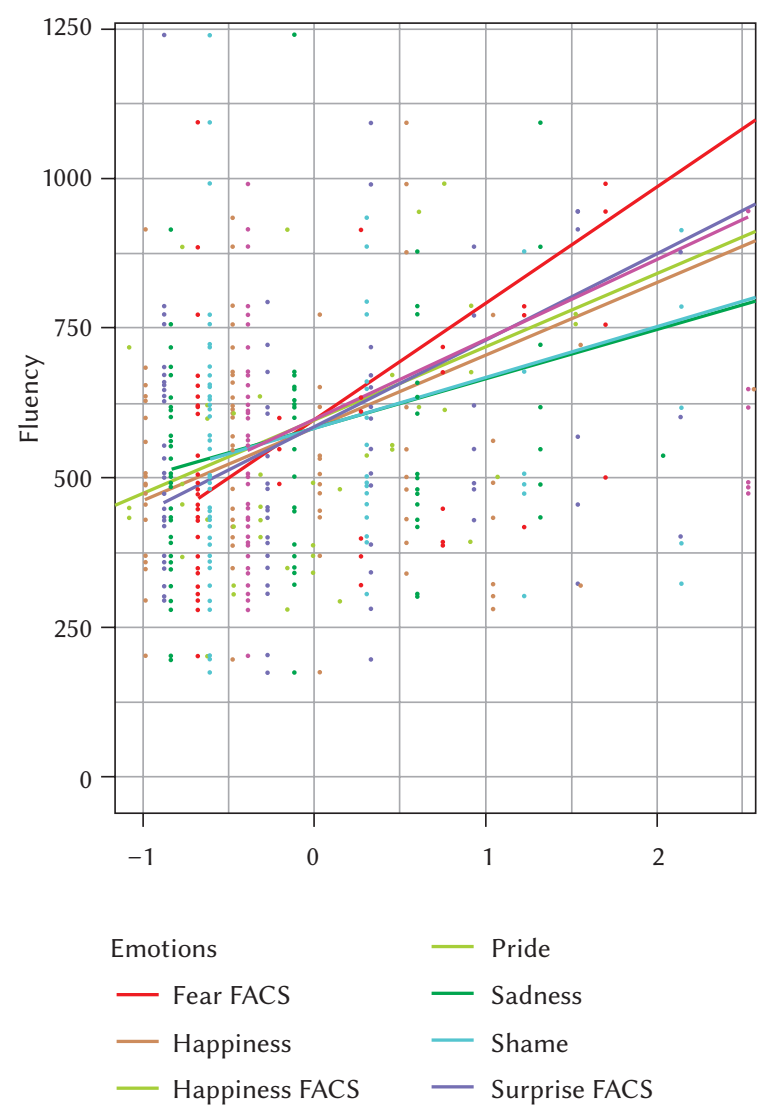

Note. $\mathrm{x}$-axis: normalized emotion frequency score measured by FACS (Fear FACS, Happiness FACS, Surprise FACS) and normalized emotion score measured by the self-report scale (Happiness, Pride, Sadness, Shame).

Figure 2. Relationship between verbal fluency and emotions - significant correlations. 
Table 3

Comparison of correlation coefficients from tables 1 and 2 between emotions and fluency

\begin{tabular}{lcccccc}
\hline & \multicolumn{2}{c}{ Fluency } & \multicolumn{2}{c}{ Positive fluency } & \multicolumn{2}{c}{ Negative fluency } \\
\cline { 2 - 6 } & $t$ & $p$ adj. & $t$ & $p$ adj. & $t$ & $p$ adj. \\
\hline Happiness & -0.37 & 1.0000 & -2.79 & 0.0640 & -2.83 & 0.0627 \\
Surprise & 1.91 & 0.5310 & 1.95 & 0.4320 & 1.87 & 0.5850 \\
Fear & $\mathbf{3 . 3 5}$ & $\mathbf{0 . 0 1 3 2}$ & 2.83 & 0.0638 & 2.23 & 0.2800 \\
Disgust & 0.76 & 1.0000 & -0.2 & 1.0000 & 1.23 & 1.0000 \\
Contempt & -0.16 & 1.0000 & -0.35 & 1.0000 & -0.29 & 1.0000 \\
Anger & -0.12 & 1.0000 & -0.24 & 1.0000 & -0.77 & 1.0000 \\
Sadness & -0.8 & 1.0000 & -1.58 & 0.8400 & -0.93 & 1.0000 \\
\hline
\end{tabular}

Note. $t$ - Steiger's test result; $p$ adj. - two-tailed significance of the test with Holm's adjustment for multivariate testing.

fluency measure. For this purpose, we performed a Steiger's (1980) test, which allows the difference between two correlations (e.g., $r_{\mathrm{ab}}-r_{\mathrm{ac}}$ ) to be determined when one of the variables is common between them and when the correlation between the remaining variables has to be taken into account $\left(r_{\mathrm{bc}}\right)$. Correlation coefficients between FACS scores and self-report scores were not high and did not exceed $r=.30$. Taking into account the overlapping variance for each of the emotions, we found a significant difference in the values of correlation coefficients for fear $(t(88)=3.35$, $p=.002, r_{\text {FACS }}=.54>r_{\text {self-rep }}=.14, d=.71$ ). The remaining correlations of scores on scales measuring emotions with fluency did not differ significantly, though it is worth noting the associations of positive and negative fluency with happiness, which we found in the case of self-report scales (Table 3).

\section{DISCUSSION}

In our study, the conceptualization of trait anxiety was performed in accordance with the model developed by Weinberger, Schwartz, and Davidson (1979; Myers, 2000, 2010), assuming the existence of truly high-anxious people, truly low-anxious ones, and repressors - unaware of their high-anxious nature. In Hypothesis 1, we postulated that individuals with specific styles of coping with stress would differ in terms of overall verbal fluency understood as loquaciousness in a potentially emotion-inducing situation. We also expected that participants from the three groups distinguished would react differently in a situation of speaking about their own positive traits compared to the situation of revealing negative aspects of themselves. Unfortunately, we did not observe the expected differences between the groups: high-anxious individuals did not generate longer utterances in answer to the question about the aspect of themselves that they disliked. This result stands in contrast to the findings of previous studies, which suggested that, through the mechanism of attentional bias, trait anxiety leads to stronger focus on negative or threatening stimuli (Derakshan \& Eysenck, 1999; Eysenck, 2000; Szepietowska \& Gawda, 2011). In our study it was not predispositions in the form of personality traits but actually experienced emotional states that were associated with loquaciousness. Only the number of silent pauses differentiated the groups distinguished. High-anxious individuals less often made silent pauses in their utterances, which may indicate their anxious attitude towards utterance breaks.

Hypotheses 2 and 3, postulating a relationship between emotional states and verbal fluency, were confirmed by the results. The Facial Action Coding System (FACS) is a method that makes it possible to capture a person's emotional state when the person himself or herself has limited insight into that state. Neurological studies have unambiguously proved that the involuntary facial expressions produced automatically in response to an emotional stimulus are governed by a center in the brain called the extrapyramidal system - as opposed to any kinds of movements of muscles controlled by the phylogenetically younger pyramidal system (Ekman, Friesen, \& Ancoli, 1980). For this reason, FACS results are regarded as having higher validity (due to the persons' very limited possibilities of controlling their own involuntary facial movements) compared to introspective methods such as rating scales, which are sensitive to motives of both unconscious self-deception and conscious impression management.

Fear recognized by means of the FACS turned out to be the emotion that was the most strongly correlated with overall verbal fluency. The state of fear increased loquaciousness both in answer to the question about the liked aspect of oneself and in answer 
to the question about the disliked trait. The correlation was significantly stronger than in the case of fear measured with rating scales, which turned out not to be associated with fluency measures. Of the remaining emotions measured with the FACS, loquaciousness was also associated with surprise and, the least strongly, with happiness. Emotions such as anger, disgust, contempt, and sadness did not correlate with loquaciousness. The reason for the lack of correlation may be the fact that they were rarely manifested. Participants' emotional states were evoked by a potentially stressful speech which triggers fear, shame or anxiety. Emotions like anger, sadness, disgust or contempt might have been evoked as a consequence of talking about the negative aspects of themselves. Nevertheless, they appeared rather rarely.

Emotions measured with rating scales - conscious emotions, which a person is able to name - turned out to be associated with verbal fluency as well. The highest correlation with overall fluency was found in the case of shame, which was slightly more strongly associated with loquaciousness in answer to the question about the disliked aspects of oneself and less strongly when speaking about the liked aspects. Also happiness, and - less strongly - sadness and pride correlated positively with verbal fluency; the last of these exhibited a fairly strong association with loquaciousness in answer to the question about the liked aspect of oneself.

The structure of results shows that the participants' behavior in the form of loquaciousness in the social situation of speaking in front of an audience was more strongly influenced by emotions resulting from the affectively stimulating situation than by stable personality traits. The activation theories of emotion, linking the intensity of emotions with the level of arousal of the central nervous system, may be helpful in explaining this pattern. Hebb (1946a, 1946b) believes that emotions correlate directly with activation but are not identical with it, since the most important component of emotions is thought processes; for example, fear is activation accompanied by images of trauma, and happiness is activation combined with a desire for permanent contact with the object that gives happiness. According to Arnold (1960), the emotional process leads to a tendency to act, and although these activities may be different, their common feature is the relatively high dynamics and limited intellectual control. Though regarded as historic, the activation theory of emotion seems to explain the obtained results well. In our participants, sitting still in front of the camera and the audience, the only available activity was speaking. It turned out that those emotions which, as Hebb assumed, were related to an increased level of activation (fear, happiness, pride) did indeed correlate with loquaciousness.

An alternative explanation can be sought in cognitive theories of emotion. In this perspective, verbal fluency is treated as one of the executive functions, beside processes such as: planning and monitoring current activity, predicting outcomes, suppressing reactions, or shifting attention between parallel tasks. It has been found that fluency, particularly phonemic fluency, is associated with the capacity of working memory and other measures of executive functions (Miyake et al., 2000; Rosen \& Engle, 1997). Executive functions play an immensely important role in emotion regulation. In a very interesting study, Gyurak and colleagues (2012) investigated the relationship between four executive functions, including verbal fluency, and emotion regulation capacity in a situation of watching an emotionally stimulating film. In a situation when the participants in the study were given the task of hiding their emotions, verbal fluency turned out to be the only function that predicted the emotional response. Higher scores on verbal fluency were associated with weaker emotional responses. In the opposite situation, when the participants in the study were instructed to enhance their emotions, verbal fluency again turned out to predict emotional response the best. High scores on fluency were associated with more emotional reactions.In the study by Gyurak and colleagues (2012), verbal fluency was the most strongly and unfailingly associated with emotion regulation capacity. It can therefore be concluded that, in our study, the relationship between some emotions and fluency reflected the attempts to cope with and regulate these emotions. Probably the presence of the camera and the audience resulted in the participants trying to down-regulate the emotions experienced in order to behave in accordance with the accepted standards, which was reflected in loquaciousness.

Our study illustrates an interesting aspect of the mutual relations between cognition and emotions. As has been stressed by Kocowski (2010), emotions influence the course of cognitive processes (including verbal fluency), and even negative emotions are better than their absence. This is illustrated by the experiment in which students performed their tasks in different kinds of emotional atmosphere. In the first group, the investigators induced anxiety and stress by simulating a situation of assessing their results. In the second group, positive mood was induced by a comic actor, and in the third group no emotions were induced. The results were the best in the group that performed the tasks in a positive atmosphere, and the worst in the group in which no emotions were induced. It should be remembered however, that - in accordance with the Yerkes-Dodson law excessive arousal or stress has a destructive influence on cognitive processes, and the boundary between its optimal and excessive levels is difficult to define. In future studies in emotional arousal and fluency, it would be advisable to introduce better control of the intensity of emotions in order to capture the mo- 
ment when it ceases to stimulate and starts to disturb the individual's cognitive functioning. In our study, the stimulating influence of strong emotions was reflected in the observed relationship between some emotions and verbal fluency disorders in the form of vocalized pauses, silent pauses, and repetitions of the same words.

The optimal level of stimulation depends on individual differences. The approach to fluency in terms of a process supporting the regulation of emotional arousal suggests that, in future studies, personality moderators of the relations between emotions and verbal fluency should be sought. Dimensions such as extraversion, verbal and emotional intelligence, as well as temperamental traits such as emotional reactivity and resistance from Strelau's (2006) regulatory theory of temperament seem to be promising, and so does self-directedness from Cloninger's psychobiological model of personality, understood as the ability to direct, regulate, control, and adjust one's behavior to situational demands (Cloninger, Svrakic, \& Przybeck, 1993). Of the more recent conceptions, research on emotional creativity also seems to be interesting; it postulates that emotions are phenomena appearing involuntarily but can be steered at will and used for better adjustment to the environment (Brackett, Ivacevic, \& Mayer, 2007). Emotionally creative individuals regard situations of threat as a challenge, which they eagerly take up and emotionally experience (Jasielska, 2002). All in all, the phenomenon of affective fluency appears to be much more complex than it was assumed to be in classic studies, and the analysis of personality and situational determinants of this process is an interesting area for further exploration.

\section{References}

Alm, P. A. (2004). Stuttering, emotions, and heart rate during anticipatory anxiety: A clinical review. Journal of Fluency Disorders, 29, 123-133.

Argaman, O. (2010). Linguistic markers and emotional intensity. Journal of Psycholinguistic Research, 39, 89-99.

Arnold, M. (1960). Emotion and personality. New York: Columbia University Press.

Asendorph, J. A., \& Scherer, K. R. (1983). The discrepant repressor: Differentiation between low anxiety, high anxiety, and repression of anxiety by autonomic-facial-verbal patterns of behavior. Journal of Personality and Social Psychology, 45, 1334-1346.

Atchley, R. A., Hardi, S. S., \& Enole, A. (2003). Hemispheric asymmetry in the processing of emotional content in word meanings: The effect of current and past depression. Brain and Language, 104, 33-41.

Bartolic, E., Basso, M., Schefft, B., Glauser, T., \& Titanic-Schefft, M. (1999). Effects of experimental- ly-induced emotional states on frontal lobe cognitive task performance. Neuropsychologia, 37, 677-683.

Blanchard, D. C., \& Blanchard, R. J. (2008). Defensive behaviors, fear, and anxiety. In R. J. Blanchard, D. C. Blanchard, G. Griebel, \& D. Nutt (Eds.), Handbook of anxiety and fear (Vol. 17, pp. 63-79). Amsterdam, The Netherlands: Academic Press. doi: 10.1016/S1569-7339(07)00005-7

Brackett, M. A., Ivacevic, Z., \& Mayer, J. D. (2007). Emotional intelligence and emotional creativity. Journal of Personality, 75, 199-236. doi: 10.1111/ j.1467-6494.2007.00437.x

Calev, A., Nigal, D., \& Chazan, S. (1989). Retrieval from semantic memory using meaningful and meaningless constructs by depressed, stable bipolar and manic patients. British Journal of Clinical Psychology, 28, 67-73.

Clark, L., Iversen, S. D., \& Goodwin, G. M. (2001). The influence of positive and negative mood states on risk taking, verbal fluency, and salivary cortisol. Journal of Affective Disorders, 63, 179-187.

Cloninger, C. R., Svrakic, D. M., \& Przybeck, T. R. (1993). A psychobiological model of temperament and character. Archives of General Psychiatry, 50, 975-990.

Crowne, D. P., \& Marlowe, D. (1960). A new scale of social desirability independent of psychopathology. Journal of Consulting Psychology, 24, 349-354.

Crowne, D. P., \& Marlowe, D. A. (1964). The approval motive: Studies in evaluative dependence. New York: Wiley.

Daniluk, B., \& Szepietowska, E. M. (2009). Zaburzenia pamięci w następstwie uszkodzeń mózgu [Memory disorders following brain injuries]. In Ł. Domańska \& A. R. Borkowska (Eds.), Podstawy psychologii klinicznej [Foundations of clinical psychology] (pp. 261-279). Lublin: Maria Curie-Skłodowska University Press.

Derakshan, N., \& Eysenck, M. W. (1997a). Repression and repressors: Theoretical and experimental approaches. European Psychologist, 2, 235-246.

Derakshan, N., \& Eysenck, M. W. (1997b). Interpretive biases for one's own behavior and physiology in high-trait-anxious individuals and repressors. Journal of Personality and Social Psychology, 73, 816-825.

Derakshan, N., \& Eysenck, M. W. (1999). Are repressors self-deceivers or other-deceivers? Cognition and Emotion, 13, 1-17.

Derakshan, N., \& Eysenck, M. W. (2001a). Manipulation of focus of attention and its effects on anxiety in high-anxious individuals and repressors. Anxiety, Stress, \& Coping, 14, 173-191.

Derakshan, N., \& Eysenck, M. W. (2001b). Effects of focus of attention on experienced anxiety in high-anxious, low-anxious, defensive high-anxious, 
and repressor individuals. Anxiety, Stress, \& Coping, 14, 285-300.

Donges, U. S., Jachmann, A., Kersting, A., Egloff, B., \& Suslow, T. (2015). Attachment anxiety and implicit self-concept of neuroticism: Associations in women but not men. Personality \& Individual Differences, 72, 208-213. doi: 10.1016/j. paid.2014.08.043

Draheim, S. E. (2001). System Kodowania Ruchów Twarzy (FACS) jako metoda mierzenia zachowań mimicznych: Procedura - rzetelność - zastosowania [Facial Action Coding System (FACS) as a method of measuring facial expressions: procedure - reliability - applications]. Psychologia - Etologia - Genetyka, 3/4, 97-113.

Ekman. P., \& Friesen, W. V. (1971). Constants across cultures in the face and emotion. Journal of Personality and Social Psychology, 17, 124-129. doi:10.1037/h0030377

Ekman, P., \& Friesen, W. V. (1978). Facial Action Coding System (FACS): A technique for the measurement of facial actions. Palo Alto, CA: Consulting Psychologists Press.

Ekman, P., Friesen, W. V., \& Ancoli, S. (1980). Facial signs of emotional experience. Journal of Personality and Social Psychology, 39, 1125-1134.

Ekman, P., Friesen, W. V., \& Hager, J. C. (2002), Facial Action Coding System. The manual on CD ROM. Salt Lake City, UT: Research Nexus Division of Network Information Research Corporation.

Ekman, P., \& Rosenberg, E. L. (Eds.) (1997). What the face reveals. Basic and applied studies of spontaneous expression. Using the Facial Action Coding System (FACS). New York: Oxford University Press.

Eysenck, M. W. (2000). A Cognitive Approach to Trait Anxiety. European Journal of Personality, 14, 463476.

Ezrati-Vinacour, R., \& Levin, I. (2004). The relationship between anxiety and stuttering: A multidimensional approach. Journal of Fluency Disorders, 29, 135-148.

Gawda, B. (2007). Ekspresja pojęć afektywnych w narracjach osób z antyspoteczna osobowościq [The expression of affective concepts in narratives of individuals with antisocial personality disorder]. Lublin: Maria Curie-Skłodowska University Press.

Gawda, B., \& Szepietowska E. M. (2015). Treść pojęć Radość i Strach w okresie dorosłości - fluencja werbalna jako narzędzie opisu pojęć emocjonalnych [The content of the concepts of Happiness and Fear in adulthood: Verbal fluency as an instrument for describing emotional concepts]. Psychologia Rozwojowa, 20, 57-72.

Gawda, B., \& Szepietowska E. M. (2012). Nastrój depresyjny a fluencja słowna [Depressive mood and verbal fluency]. Psychologia - Etologia - Genety$k a, 25,25-40$.
Gawda, B., \& Szepietowska E. M. (2011). Fluencja słowna i jej uwarunkowania [Verbal fluency and its determinants]. Psychologia - Etologia - Genetyka, 23, 63-90.

Gyurak, A., Goodkind, M. S., Kramer, J. H., Miller, B. L., \& Levenson, R. W. (2012). Executive functions and the down-regulation and up-regulation of emotion. Cognition and Emotion, 26, 103-118.

Hebb, D. O. (1946a). Emotion in man and animal: An analysis of the intuitive processes of recognition. Psychological Review, 53, 88-106.

Hebb, D. O. (1946b). On the nature of fear. Psychological Review, 53, 259-276.

Jasielska, A. (2002). Emocje a płeć. Analiza w kontekście twórczości emocjonalnej [Emotion and sex: An analysis in the context of emotional creativity]. In A. Hulewska, A. Jasielska, \& M. Ziarko (Eds.), Interdyscyplinarne studia nad ptcia. Od polaryzacji ptciowej do polaryzacji rodzajowej [Interdisciplinary studies on sex: From sex polarization to gender polarization]. Poznań: Humaniora Foundation Press.

Jasielska, A. (2007). Zastosowanie analizy transkrypcji do pomiaru inteligencji emocjonalnej [The application of transcription analysis to emotional intelligence measurement]. Psychologia. Edukacja i Społeczeństwo, 4, 29-45.

Kasl, S. V., \& Mahl, G. F. (1965). The relationship of disturbances and hesitations in spontaneous speech to anxiety. Journal of Personality and Social Psychology, 1, 425-433.

Keogh, E. (2004). Investigating invariance in the factorial structure of the anxiety sensitivity index across adult men and women. Journal of Personality Assessment, 83, 153-160.

Kocowski, T. (2010). Stres-potrzeby-twórczość [Stress - needs - creativity]. Poznań: Polskie Towarzystwo Przyjaciół Nauk.

Mahl, G. F. (1956). Disturbances and silences in the patient's speech in psychotherapy. Journal of $A b$ normal Psychology, 53, 1-15.

Mahl, G. F. (1987a). Everyday Disturbances of Speech. New York: Plenum Press.

Mahl, G. F. (1987b). Explorations in Nonverbal and Vocal Behavior. Hillsdale: Lawrence Erlbaum Associates.

Meyer, T. J., Miller, M. L., Metzger, R. L., \& Borkovec, T. D. (1990). Development and validation of the Penn State Worry Questionnaire. Behaviour Research and Therapy, 28, 487-495. doi: 10.1016/00057967(90)90135-6

Miyake, A., Friedman, N. P., Emerson, M. J., Witzki, A. H., Howerter, A., \& Wager, T. D. (2000). The unity and diversity of executive functions and their contributions to complex "frontal lobe" tasks: A latent variable analysis. Cognitive Psychology, 41, 49-100. 
Morreale, S. P., Spitzberg, B. H., \& Barge J. K. (2001). Human Communication: Motivation, Knowledge and Skills. Wadsworth: Thomson Learning Inc.

Myers, L. B. (2000). Identifying repressors: A methodological issue for health psychology. Psychology and Health, 15, 205-214.

Myers, L. B. (2010). The importance of the repressive coping style: Findings from 30 years of research. Anxiety, Stress, \& Coping, 30, 3-17.

Noël, V. A., Lewis, K., Francis, S. E., \& Mezo, P. G. (2013). Relationships between the multiple dimensions of anxiety sensitivity and symptoms of anxiety and depression in men and women. Journal of Cognitive and Behavioral Psychotherapies, 13, 333-353.

Obrębska, M. (2013). Styl mówienia w schizofrenii [Speaking style in schizophrenia]. Poznań: Adam Mickiewicz University Press

Obrębska, M., \& Kleka, P. (2016). Gadatliwość kobiet: prawda czy stereotyp? [Women's talkativeness: Truth or stereotype?] In J. Mampe, H. Makurat, Ł. Owczinnikowa, \& F. Marzouk (Eds.), Socjolingwistyczne badania w teorii i praktyce. Ujecie interdyscyplinarne [The theory and practice of sociolinguistic research: An interdisciplinary perspective] (pp. 77-86). Gdańsk: University of Gdansk Press.

Obrębska, M., \& Zinczuk-Zielazna, J. (2016). Style radzenia sobie z bodźcami zagrażającymi a częstość użycia partykuł w wypowiedziach jako wskaźnik lęku w sytuacji społecznej ekspozycji [Styles of coping with threatening stimuli and the frequency of particle use in utterances as an indicator of anxiety in situations of social exposure]. Socjolingwistyka, 30, 261-275.

Obrębska, M., \& Obrębski, T. (2007). Lexical and Grammatical Analysis of Schizophrenic Patients' Language: A Preliminary Report. Psychology of Language and Communication, 11, 63-72.

Perkins, A. M., Inchley-Mort, S. L., Pickering, A. D., Corr, P. J., \& Burgess, A. P. (2012). A facial expression for anxiety. Journal of Personality and Social Psychology, 102, 910-924.

Reiss, S., Peterson, R. A., Gursky, D. M., \& McNally, R. J. (1986). Anxiety sensitivity, anxiety frequency and the predictions of fearfulness. Behaviour Research and Therapy, 24, 1-8. doi: 10.1016/00057967(86)90143-9

Reynolds, A., Richards, G., de la Iglesia, B., \& Rayward-Smith, V. (1992). Clustering rules: A comparison of partitioning and hierarchical clustering algorithms. Journal of Mathematical Modelling and Algorithms, 5, 475-504. doi: http:// dx.doi.org/10.1007/s10852-005-9022-1.

Rosen, V. M., \& Engle, R. W. (1997). The role of working-memory capacity in retrieval. Journal of Experimental Psychology: General, 126, 211-227.
Schwartz S., Baldo J., Graves R., \& Brugger P. (2003). Pervasive influence of semantics in letter and category fluency: A multidimensional approach. Brain and Language, 87, 400-411.

Siuta, J. (1989). Zmienna aprobaty społecznej w badaniach nad zjawiskami hipnotycznymi [The social approval variable in studies of hypnotic phenomena]. Zeszyty Naukowe UJ, 5, 131-141.

Spielberger, C. D., Gorsuch, R. L., Lushene, R. E., Vagg, P. R., \& Jacobs, G. A. (1983). Manual for the State-Trait Anxiety Inventory: STAI (Form Y2). Palo Alto, CA: Consulting Psychologists Press.

Steiger, J. H. (1980). Tests for comparing elements of a correlation matrix. Psychological Bulletin, 87, 245-251.

Strelau, J. (2006). Psychologia różnic indywidualnych [The psychology of individual differences]. Warsaw: Scholar.

Szepietowska, E. M., \& Gawda, B. (2011). Ścieżkami fluencji werbalnej [Following the paths of verbal fluency]. Lublin: Maria Curie-Skłodowska University Press.

Tabert, M. H., Peery, S., Borod, J., Schmidt, M., Grunwald, I., \& Sliwinski, M. (2001). Lexical emotional expression across the life span: Quantitative and qualitative analyses of word list generation tasks. The Clinical Neuropsychologist, 15, 531-550.

Tsakanikos, E., \& Claridge, G. (2005). More words, less words: Verbal fluency as a function of "positive" and "negative" schizotypy. Personality and Individual Differences, 39, 705-713.

Weinberger, D. A., \& Davidson, M. N. (1994). Styles of inhibiting emotional expression: Distinguishing repressive coping from impression management. Journal of Personality, 62, 587-613.

Weinberger, D. A., Schwartz, G. E., \& Davidson, R. J. (1979). Low-anxious, high-anxious, and repressive coping styles: Psychometric patterns and behavioral and physiological responses to stress. Journal of Abnormal Psychology, 88, 369-380.

Wrześniewski, K., Sosnowski, T., \& Matusik, D. (2002). Inwentarz Stanu i Cechy Lęku STAI. [State-Trait Anxiety Inventory (STAI)]. Warsaw: Psychological Test Laboratory of the Polish Psychological Association.

Zimbardo, P. G., Mahl, G. F., \& Barnard, J. W. (1963). The measurement of speech disturbance in anxious children. Journal of Speech \& Hearing Disorders, 28, 362-370.

Zinczuk-Zielazna, J., \& Obrębska, M. (2016). Styles of coping and the level of dogmatism in utterance texts as an indicator of anxiety in situations of social exposure. Polish Psychological Bulletin, 47, 402-411. 